Check for updates

Cite this: Chem. Sci., 2019, 10, 10149

๑ All publication charges for this article have been paid for by the Royal Society of Chemistry

Received 20th June 2019

Accepted 16th September 2019

DOI: $10.1039 / c 9 s c 03042 \mathrm{e}$

rsc.li/chemical-science

\section{Alleviation of symptoms of Alzheimer's disease by diminishing $A \beta$ neurotoxicity and neuroinflammation $\uparrow$}

\author{
Tao Yang, (ID : Zhenzhu Zhu, (D) $\ddagger^{a}$ Enmao Yin, ${ }^{a}$ Yanqing Wang, ${ }^{b}$ Changli Zhang, ${ }^{c}$ \\ Hao Yuan, ${ }^{d}$ Hongmei Zhang, ${ }^{a}$ Suxing Jin, (D) ${ }^{a}$ Zijian Guo (D) d and Xiaoyong Wang (D) *a
}

Alzheimer's disease (AD) is one of the most prevailing neurodegenerative illnesses in the elderly. Accumulation of amyloid- $\beta$ peptide $(A \beta)$ and inflammation play critical roles in the pathogenesis and development of $A D$. Multi-target drugs may interdict the progress of $A D$ through a synergistic mechanism. A neuromodulator, 2-((1H-benzo[d]imidazole-2-yl)methoxy)benzoic acid (BIBA), consisting of an $A \beta$-targeting group and a derivative of anti-inflammatory aspirin was designed as a potential anti$A D$ agent. BIBA exhibits a remarkable inhibitory effect on the self- and metal-induced $A \beta$ aggregations and shows outstanding anti-inflammatory activity simultaneously. The neurotoxicity of $A \beta$ aggregates is attenuated, and the production of pro-inflammatory cytokines (PICs), such as IL-6, IL-1 $\beta$ and TNF- $\alpha$, in microglia stimulated by lipopolysaccharide (LPS) or $A \beta$ is reduced. Owing to the synergy between the inhibition of $A \beta$ oligomerization and downregulation of PICs, BIBA markedly prolongs the lifespan and relieves the $A \beta$-induced paralysis of $A \beta$-transgenic Caenorhabditis elegans, thus showing the potential to ameliorate the symptoms of $A D$ through inhibiting $A \beta$ neurotoxicity and deactivating microglia. These findings demonstrate that both $A \beta$ aggregation and neuroinflammation are therapeutic targets for anti$A D$ drugs, and dual-functional agents that integrate anti- $A \beta$ and anti-inflammatory capabilities have great advantages over the traditional single-target agents for AD treatment.

\section{Introduction}

Alzheimer's disease (AD) is a fatal and age-related neurodegenerative disorder characterized by memory loss and progressive cognitive impairment. ${ }^{\mathbf{1 , 2}}$ Currently, approved pharmacotherapies only provide short-term or mild relief from $\mathrm{AD}$ symptoms, but do not cure or prevent the process of $\mathrm{AD} .^{3}$ Although the exact pathogenesis of AD is elusive, amyloid cascade hypothesis is the major etiologic basis for $\mathrm{AD}$ over the past few decades. It is believed that $\mathrm{AD}$ is caused by the accumulation of amyloid- $\beta$ peptide $(A \beta)$, which initiates a sequence of pathogenic events, such as the formation of neurofibrillary tangles (NFTs) and the onset of synaptic and neuronal dysfunction or death. ${ }^{4}$ In $\mathrm{AD}$ pathogenesis, $\mathrm{A} \beta$ species, mainly $\mathrm{A} \beta 40$ and more toxic $\mathrm{A} \beta 42,{ }^{5}$ aberrantly aggregate from non-toxic

${ }^{a}$ State Key Laboratory of Pharmaceutical Biotechnology, School of Life Sciences, Nanjing University, Nanjing 210023, P. R. China. E-mail: boxwxy@nju.edu.cn ${ }^{b}$ School of Chemistry and Chemical Engineering, Yancheng Teachers University, Yancheng 224002, P. R. China

${ }^{\circ}$ Department of Chemistry, Nanjing Xiaozhuang College, Nanjing, 210017, P. R. China ${ }^{d}$ State Key Laboratory of Coordination Chemistry, School of Chemistry and Chemical Engineering, Nanjing University, Nanjing 210023, P. R. China

$\dagger$ Electronic supplementary information (ESI) available. See DOI: $10.1039 / \mathrm{c} 9 \mathrm{sc} 03042 \mathrm{e}$

$\$$ These authors contributed equally to this work. monomers into toxic oligomers, fibrils, and eventually senile plaques. Plenty of evidence suggests that $A \beta$ aggregates, especially soluble oligomers, could impair synaptic and cognitive functions. ${ }^{6}$ Thus, $A \beta$ oligomers and fibrils are regarded as the main therapeutic targets for $\mathrm{AD} .^{7}$ Since $\mathrm{A} \beta$ aggregation and its neurotoxicity could be aggravated by metal ions such as $\mathrm{Zn}^{2+}$ and $\mathrm{Cu}^{2+}$ in the $\mathrm{AD}$ brain, ${ }^{\mathbf{8}, 9}$ metal chelators that can regulate the distribution of metal ions are potential therapeutic agents for $\mathrm{AD} .^{\mathbf{1 0 , 1 1}}$ Extensive studies have focused on the reduction of $\mathrm{A} \beta$ or its aggregation by targeting $\mathrm{A} \beta$ production or clearance, ${ }^{12-15}$ and some compounds have effectively prevented the de novo aggregation of $\mathrm{A} \beta$; however, they cannot eliminate the existing $A \beta$ oligomers and plaques in the brain. ${ }^{16}$ Consequently, such strategies hardly improve the cognition of patients, and none of them have gone through clinical trials so far. ${ }^{17,18}$

On the other hand, activated microglia in the central nervous system and increased inflammatory mediators around $\mathrm{A} \beta$ plaques in the brain of $\mathrm{AD}$ patients have been related to the pathogenesis of $\mathrm{AD}$. $\mathrm{A} \beta$ and NFTs can indirectly activate immune response or microglia and lead to the release of various pro-inflammatory cytokines (PICs) and neurotoxic mediators. ${ }^{\mathbf{1 9}}$ Microglia have two phenotypes of activation: pro-inflammatory M1 and immunosuppressive $\mathbf{M} 2 .^{20}$ M1 is associated with releasing PICs, such as interleukin-1 $\beta$ (IL-1 $\beta$ ), interleukin-6 (IL$6)$, tumour necrosis factor- $\alpha$ (TNF- $\alpha$ ), superoxide, nitric oxide 
(NO), reactive oxygen species (ROS), and expressing inducible nitric oxide synthase (iNOS). These PICs and mediators not only attenuate the phagocytosis of $\mathrm{A} \beta,{ }^{21}$ but also affect the tau pathological metamorphosis, increasing tau phosphorylation and accelerating tangle formation, ${ }^{22}$ thereby inducing neurotoxicity. In addition, PICs and activated microglia could promote $A \beta$ production, exacerbating the formation of $A \beta$ fibrils and deposition. ${ }^{23,24}$ To make things worse, toxic $A \beta$ oligomers and fibrils could be recognized by some receptors expressed by microglia, ${ }^{25,26}$ triggering the microglial activation through nuclear factor-kappa B (NF- $\mathrm{B})$ or mitogen-activated protein kinases (MAPKs). ${ }^{27}$ Aging and toxic conditions in the AD brain also favour the chronic activation of microglia and reduce their phagocytic capacity and prolong neuroinflammation. ${ }^{28}$ As a result, a vicious cycle between neuroinflammation and $A \beta$ aggregation is formed, ultimately leading to the death of neurons and onset of $\mathrm{AD} .^{29,30}$ Thus, interfering with the vicious cycle may produce therapeutic effects on AD.

Anti-inflammatory drugs were expected to reduce the risk of $\mathrm{AD}$, but clinical trials for these drugs have failed. ${ }^{31-34}$ Considering the pathogenic effect of $\mathrm{A} \beta$ aggregation and neuroinflammation in $\mathrm{AD}$, we suppose that defence against both $\mathrm{A} \beta$ oligomers or plaques and PICs may produce a dual impact on the $\mathrm{AD}$ progression and protect the neurons in the brain. Herein we report a novel neuromodulator (BIBA, Fig. 1), which is a hybrid of a derivative of aspirin, a non-steroidal antiinflammatory drug, and 2-(phenoxymethyl)- $1 H$-benzoimidazole, an analogue of A $\beta$-targeting thioflavin $\mathrm{T}$ (ThT), for inhibiting the $\mathrm{A} \beta$ aggregation and neuroinflammation. As anticipated, BIBA showed remarkable inhibitory effects on selfand metal-induced $\mathrm{A} \beta$ aggregations, and exhibited obvious antiinflammatory activity by suppressing intracellular lipopolysaccharide (LPS)- or A $\beta$-induced production of PICs in microglia. Moreover, it delayed the $A \beta$-induced paralysis and increased the lifespan of transgenic Caenorhabditis elegans (C. elegans). A preliminary test suggests that BIBA could rescue the memory deficits of the amyloid precursor protein/presenilin protein 1 (APP/PS1) mice through inhibiting $A \beta$ oligomerization and overactivation of microglia. To the best of our knowledge, BIBA is the first anti-AD agent capable of regulating $A \beta$ aggregation and neuroinflammation simultaneously.

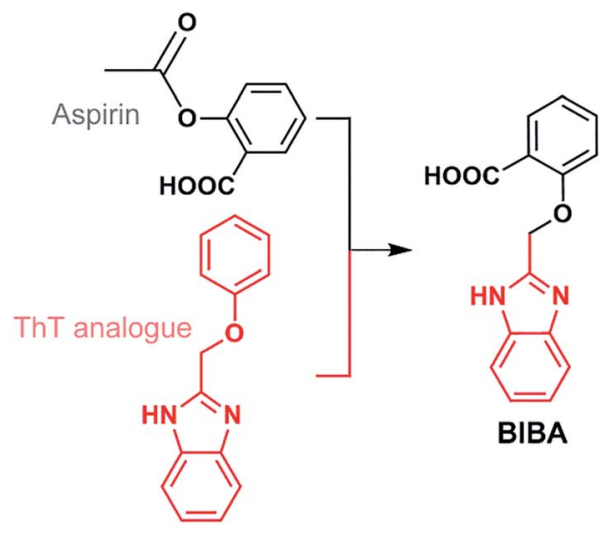

Fig. 1 Construction of BIBA.

\section{Results and discussion}

\section{Design and synthesis of BIBA}

BIBA was designed by linking an $A \beta$-targeting moiety with a derivative of aspirin. The 2-(phenoxymethyl)-1 $H$-benzoimidazole group was selected due to its high lipophilicity and affinity for $A \beta$ aggregates; ${ }^{35}$ the derivative of aspirin was chosen to suppress the generation of PICs by inhibiting cyclooxygenases (COXs). ${ }^{36}$ In addition, a low dose of aspirin could decrease $A \beta$ plaques by upregulating the transcription factor $\mathrm{EB},{ }^{37}$ and benefit the inhibition of protein aggregation and corresponding toxicity through acetyl-donating activity. ${ }^{38}$ The synthesis and characterization of BIBA are shown in Scheme S1 and Fig. S1. $\dagger$ BIBA is stable over $24 \mathrm{~h}$ in buffer ( $\mathrm{pH} 7.4$ ), suggesting that it suitable for biochemical experiments (Fig. S2 $\dagger$ ). The lipophilicity parameter $(\log P)$ of BIBA determined by the shakeflask method is $-0.04 \pm 0.01$, indicating that BIBA is more lipophilic than the aspirin derivative $(\log P=-1.40 \pm 0.07)$. According to Lipinski's "rule of five",39 BIBA could potentially cross the BBB (see Table S1 $\dagger$ ). To verify the BBB-penetrating ability, we analyzed the brains of $\mathrm{C} 57 \mathrm{BL} / 6 \mathrm{~J}$ mice after intravenous injection of BIBA by HPLC. BIBA reached its maximum in the brain at around $10 \mathrm{~min}$ and attenuated gradually at $20 \mathrm{~min}$ after injection (Fig. S3†). The results confirm that BIBA can cross the BBB.

\section{Prevention of $A \beta$ aggregation}

$\mathrm{A} \beta$ aggregations, especially those induced by $\mathrm{Zn}^{2+}$ or $\mathrm{Cu}^{2+}$, play important roles in neurodegenerative diseases, influencing both protein structures and oxidative stress. ${ }^{40}$ Therefore, the chelating behaviour of BIBA towards $\mathrm{Zn}^{2+}$ or $\mathrm{Cu}^{2+}$ was initially investigated by fluorescence titration in Tris-HCl buffer. BIBA gave sensitive fluorescence responses to both $\mathrm{Zn}^{2+}$ and $\mathrm{Cu}^{2+}$ in a $2: 1$ binding ratio (Fig. $\mathrm{S} 4 \dagger$ ), indicating that it can interact with $\mathrm{Zn}^{2+}$ or $\mathrm{Cu}^{2+}$ and potentially affect the metal-induced $\mathrm{A} \beta$ aggregations. The inhibitory effect of BIBA on $A \beta$ aggregation was examined by circular dichroism (CD) spectroscopy, which is extensively used to monitor the secondary structural conversion of proteins. As shown in Fig. 2A, the CD spectrum of A $\beta$ displays two negative peaks around 198 and $217 \mathrm{~nm}$, which are characteristics of random coils and $\beta$-sheet conformation, respectively. When $\mathrm{A} \beta$ was incubated with $\mathrm{Zn}^{2+}$ or $\mathrm{Cu}^{2+}$, the negative peak at $198 \mathrm{~nm}$ disappeared and a new positive peak emerged around $194 \mathrm{~nm}$, along with the increase of the negative peak around $217 \mathrm{~nm}$. These changes indicate that the conformation of $\mathrm{A} \beta$ is transformed from random coils to $\beta$-sheets, thus signifying the formation of $A \beta$ fibrils. The results are consistent with reported observations. ${ }^{\mathbf{4 1 , 4 2}}$ Upon addition of BIBA, the negative band centred at $217 \mathrm{~nm}$ diminished, indicating that the level of $A \beta$ fibrils was decreased. The morphological changes of $A \beta$ in the absence and presence of metal ions and/or BIBA were directly visualized by transmission electron microscopy (TEM). As shown in Fig. 2B, some fibrils were observed in the solution of $\mathrm{A} \beta$, and large amounts of mature aggregates were seen in the presence of $\mathrm{Zn}^{2+}$ and $\mathrm{Cu}^{2+}$, indicating that soluble $\beta$ sheet-rich fibrils and insoluble $A \beta$ aggregates are formed. ${ }^{42}$ 

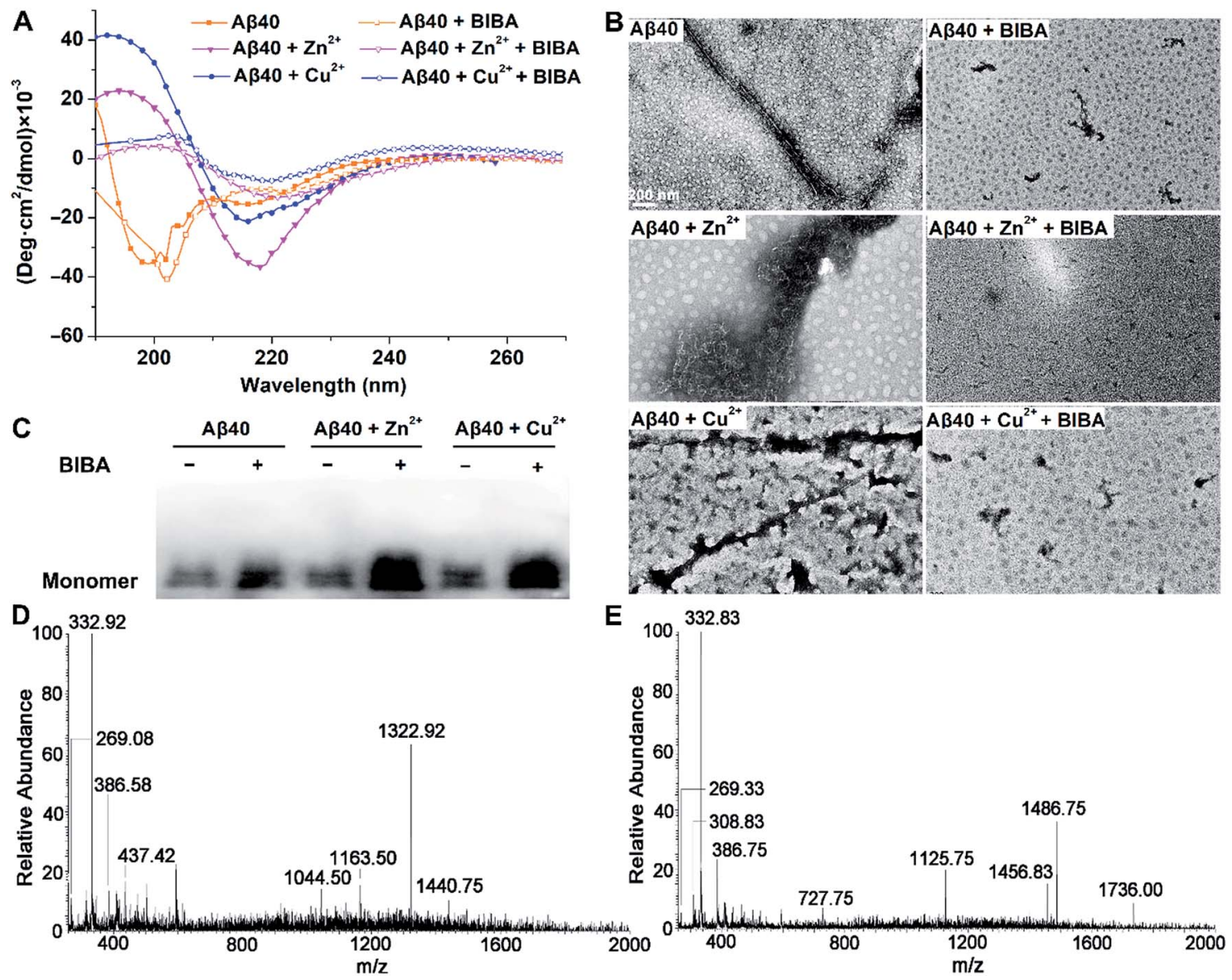

Fig. 2 Prevention of self- or metal-induced $A \beta 40$ aggregation by BIBA. (A) CD spectra, (B) TEM, and (C) Western blot of $A \beta 40$ without or with metal ions and BIBA, and ESI-MS spectra of $A \beta 40$ with (D) $\mathrm{Zn}^{2+}$ or $(\mathrm{E}) \mathrm{Cu}^{2+}$ in the presence of $\mathrm{BIBA}\left([\mathrm{A} \beta]=\left[\mathrm{Zn}^{2+} / \mathrm{Cu}^{2+}\right]=10 \mu \mathrm{M}\right.$ and $[\mathrm{BIBA}]=20$ $\mu \mathrm{M})$.

Massive $A \beta$ aggregates were changed into short fibrils or sporadic granule-like species after incubation with BIBA, showing that the $A \beta$ aggregations with or without metal ions were suppressed. The Western blot also showed that BIBA could inhibit the formation of insoluble $A \beta$ fibrils and increase the number of monomers (Fig. 2C). The effect of BIBA on A $\beta 42$ aggregation was also analyzed by using CD spectra, TEM and Western blot (Fig. S5 $\dagger$ ); the results are consistent with those for $A \beta 40$. The CD spectra of $A \beta 42$ were somewhat different from those of $A \beta 40$ possibly because $A \beta 42$ aggregated into fibrils more quickly than $A \beta 40$, which was consistent with previous reports. $^{43-45}$

The interactions of BIBA with the $\mathrm{Zn}^{2+}$ - or $\mathrm{Cu}^{2+}$-induced $\mathrm{A} \beta 40$ aggregates were further investigated by ESI-MS. As shown in Fig. 2D and E, no peaks assignable to A $\beta 40$ species or BIBA$A \beta 40$ adducts are observed after the co-incubation of $A \beta 40$, metal ions and BIBA (see Tables S2 and S3†), suggesting that no covalent interactions occurred between BIBA and A $\beta 40$. Noticeably, several peaks corresponding to BIBA-metal ions and BIBA-metal-A $\beta 40$ adducts were observed. All these results indicate that BIBA exhibits high potential to dissociate the $A \beta$ aggregates without or with metal ions, and the chelation is involved in the inhibition of metal-induced $A \beta$ aggregation.

\section{Attenuation of $\mathbf{A} \beta$ neurotoxicity}

The transition of $\mathrm{A} \beta$ from nontoxic monomers to toxic oligomers and plaques was believed to be a crucial reason for the neurotoxicity in $\mathrm{AD}{ }^{46}$ In addition, $\mathrm{Zn}^{2+}$ and $\mathrm{Cu}^{2+}$ are able to stabilize the soluble $A \beta 42$ oligomers and hence aggravate the neuron death. ${ }^{47,48}$ The effect of BIBA on the $A \beta$-induced neurotoxicity in the absence and presence of $\mathrm{Zn}^{2+}$ or $\mathrm{Cu}^{2+}$ was tested in the mouse neuroblastoma Neuro2a (N2a) cell line, which was usually used to evaluate the drug toxicity in the study of $\mathrm{AD} .^{49}$ As shown in Fig. 3A, the viability of N2a cells treated with $\mathrm{A} \beta 42$ alone or in the presence of metal ions was less than $70 \%$, which is consistent with a literature report; ${ }^{50}$ the viability increased remarkably when the cells were coincubated with A $\beta 42$ and BIBA in the presence and absence of metal ions. The results suggest that BIBA can effectively attenuate the cytotoxicity of $A \beta 42$ aggregates with or without metal ions. BIBA per se was almost non-toxic toward N2a cells even at $50 \mu \mathrm{M}$ (Fig. S6†).

It is known that neuronal apoptosis induced by neurotoxic $\mathrm{A} \beta$ aggregates plays a central role in triggering $\mathrm{AD}$. The prevention of such apoptosis may represent an effective way for the treatment of $\mathrm{AD}$. To explore the capability of BIBA to 

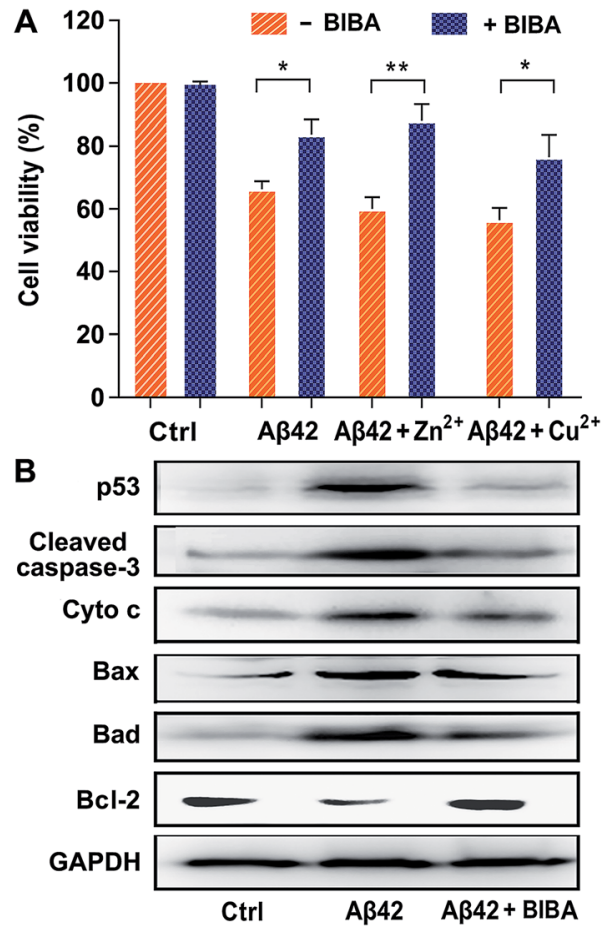

Fig. 3 (A) Viability of N2a cells in the presence of $A \beta 42$ without or with metal ions and BIBA after incubation for $24 \mathrm{~h}$ determined by the MTT assay, and (B) expression of apoptosis-related proteins in N2a cells stimulated with $A \beta 42$ aggregates in the presence and absence of BIBA for $24 \mathrm{~h}$ detected by the Western blot $(n=3 ; * * P<0.001$ and $* P<0.01$; $[A \beta]=\left[\mathrm{Zn}^{2+} / \mathrm{Cu}^{2+}\right]=10 \mu \mathrm{M}$, and $\left.[\mathrm{BIBA}]=20 \mu \mathrm{M}\right)$

block the signalling pathway to $A \beta$-induced neuronal cell death, the expression of apoptotic proteins in N2a cells stimulated by $\mathrm{A} \beta 42$ in the presence of BIBA was measured by the Western blot. Among them, p53 is related to the induction of neuronal apoptosis in $\mathrm{AD}$ and believed to be one of the targets of nuclear $A \beta ;{ }^{51}$ cleaved caspase-3 plays a critical role in the apoptotic signalling pathway; ${ }^{52}$ cytochrome c (Cyto c) is released from the mitochondria into the cytoplasm to initiate apoptosis; Bax and Bad are pro-apoptotic proteins in the Bcl-2 protein family; and Bcl-2 is an anti-apoptotic protein that inhibits the activation of the apoptotic pathway. As shown in Fig. 3B, after treatment with $\mathrm{A} \beta 42$, the expression of $\mathrm{p} 53$, cleaved caspase-3, Cyto c, Bax, and Bad was dramatically increased, but that of Bcl-2 was decreased; however, after addition of BIBA, the expression of pro-apoptotic proteins was down-regulated obviously, while that of Bcl-2 was upregulated. The results suggest that BIBA can prevent the apoptosis of neural cells induced by $\mathrm{A} \beta$.

\section{Effect on paralysis and lifespan of transgenic C. elegans}

Transgenic C. elegans strains expressing the human $\mathrm{A} \beta$ gene in muscles or neurons are widely used as in vivo models of $\mathrm{AD}$ for examining the accumulation and toxicity of $A \beta$ and screening potential drugs, because the worms are simple in culturing and fast in generation, and have 302 neurons in hermaphrodites, a well-characterized nerve system, and a high level of homology with the human genome..$^{53-57}$ The expression of the $A \beta$ gene in muscles of C. elegans is associated with severe age-progressive paralysis, ${ }^{58}$ which is an apparent symptom and also a measurable phenotype regarded as a consequence of $A \beta$ toxicity in these AD models. Hence, the effect of BIBA on the paralysis was investigated. In transgenic C. elegans strain CL4176, the aggregation of $A \beta 1-42$ in the muscle tissue is temperature-inducible,$^{59}$ which results in the time-dependent aggregation of $A \beta$ and paralytic phenotype. ${ }^{60}$ This kind of worms produces low levels of $\mathrm{A} \beta$ and moves as rollers when grown at $15{ }^{\circ} \mathrm{C}$ (Fig. $4 \mathrm{~A}$ top), and generates a large amount of $\mathrm{A} \beta$ and becomes straight and loses the moving ability when the temperature was upshifted to $25{ }^{\circ} \mathrm{C}$ (Fig. $4 \mathrm{~A}$ bottom). Meanwhile, transgenic $C$. elegans strain CL802 that does not express the A $\beta$ gene in muscle tissue ${ }^{61}$ and aspirin-treated CL4176 were used as the controls. As expected, BIBA and aspirin decreased the percent of paralysis from $58.7 \%$ to $6.3 \%$ and $17.4 \%$, respectively, at $34 \mathrm{~h}$ after the temperature upshift (Fig. 4B). In addition, $92.6 \%$ of the untreated worms became paralyzed after $36 \mathrm{~h}$, while only $27.2 \%$ of the BIBA-treated worms were paralyzed. By contrast, the mobility of the CL802 strain did not alter. These results indicate that BIBA can more effectively protect transgenic C. elegans against the $A \beta$-induced paralysis than aspirin.

The effect of BIBA on the lifespan of CL4176 worms was further examined by analyzing the overall nematode survival. As shown in Fig. 4C and D, BIBA caused a significant increase in the lifespan of CL4176 worms as compared with the control, suggesting that it can mitigate the $A \beta$-related pathological threat to the worms. The same dose of aspirin was less effective for increasing the lifespan, which was consistent with the paralysis assay. We speculate that the advantages may arise from the synergistic effect of two functional moieties in BIBA. The administration of BIBA to wild-type (N2) worms at the L2 larval stage did not modify their survival (Fig. S7 $\dagger$ ), indicating that its toxicity is negligible.

The $\mathrm{A} \beta$ deposits in transgenic CL4176 were first examined by thioflavin $\mathrm{S}$ (ThS, a dye for $\mathrm{A} \beta$ plaques) staining, which could reflect the inhibitory effect of BIBA on $A \beta$ aggregation through green fluorescence. Fig. $4 \mathrm{E}$ shows that the $\mathrm{A} \beta$ deposits were greatly reduced in worms fed with BIBA, while they did not respond obviously to aspirin. Furthermore, the $A \beta$ species from the CL4176 worms fed with or without BIBA were analyzed by the Western blot. As shown in Fig. $4 \mathrm{~F}$, the $A \beta$-immunoreactive (6E10) bands of the tissues indicate that BIBA evidently reduced the amount of toxic $\mathrm{A} \beta$ oligomeric species. The expression of COX-2, TNF- $\alpha$, IL-6 and IL-1 $\beta$ in CL4176 worms was also measured by the Western blot after the worms were fed with BIBA, aspirin or vehicle. As shown in Fig. $4 \mathrm{G}$ and $\mathrm{H}$, the expression of PICs decreased markedly as compared with the control group. Apparently, the extension of lifespan and delay of paralysis in CL4176 by aspirin result from its anti-inflammatory ability rather than inhibitory ability to $A \beta$ oligomerization, while the protective effect of BIBA against $A \beta$-induced toxicity in the worms arises from its inhibition of $A \beta$ oligomerization and deposition as well as its anti-inflammatory ability. Aspirin alone exhibits a much weaker effect than BIBA due to the lack of anti$\mathrm{A} \beta$ aggregation ability. 
A
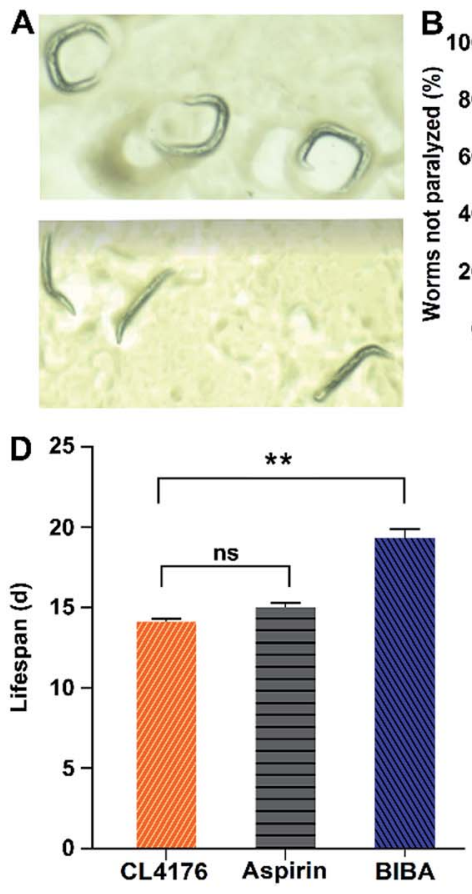

$\mathbf{F}$

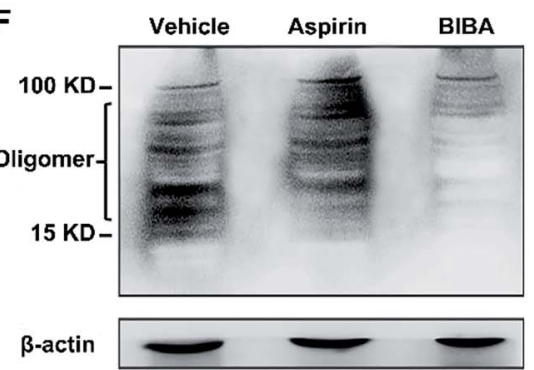

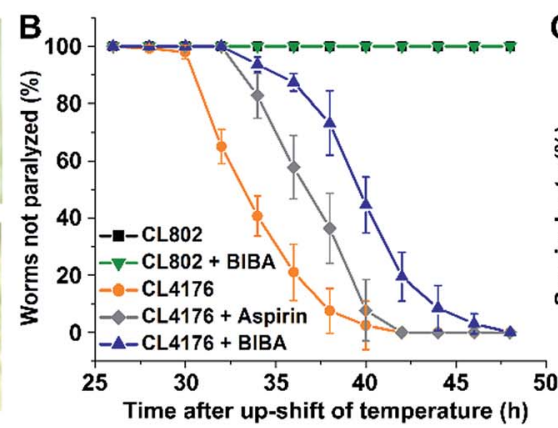
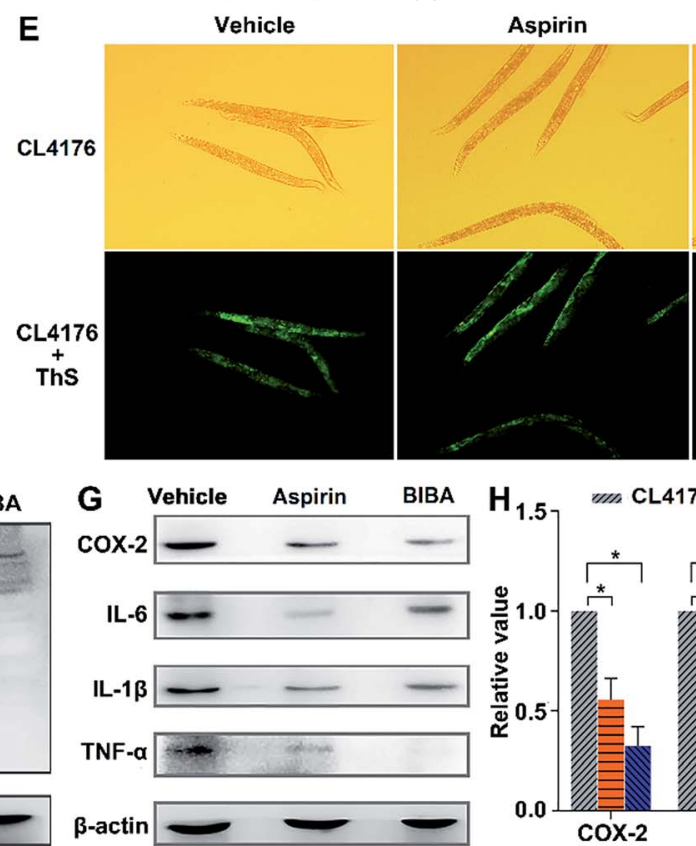

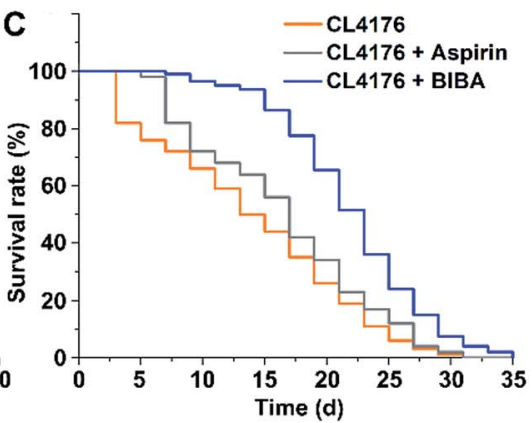

BIBA
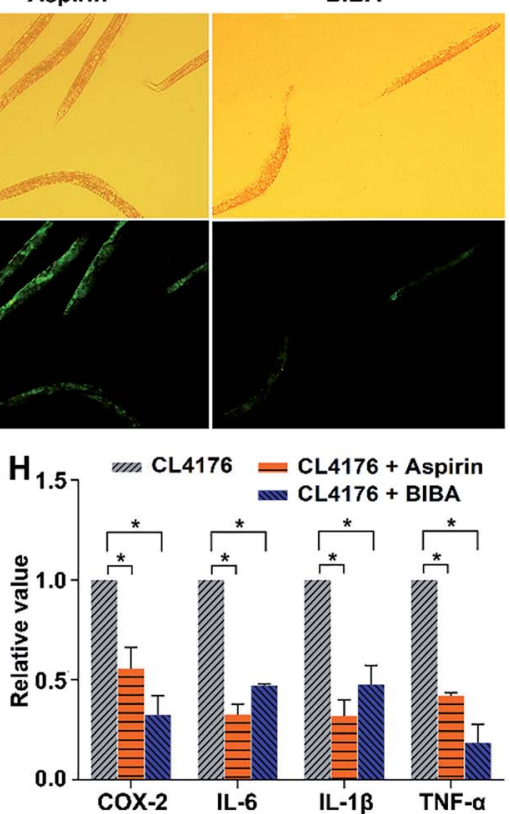

Fig. 4 (A) Different motion modes of CL4176, (B) effects of drugs on the paralysis of CL802 or CL4176 worms at $25^{\circ} \mathrm{C}$, (C) survival curves of $\mathrm{CL} 4176$ worms after treatment with drugs at $15^{\circ} \mathrm{C}$, (D) mean lifespan of CL4176 worms after drug treatment calculated by using GraphPad Prism 7. (E) photos of CL4176 worms after drug treatment at $25{ }^{\circ} \mathrm{C}$ for $48 \mathrm{~h}$ and then stained with ThS, (F) Western blot of $A \beta$ species and (G) inflammatory mediators in CL4176 worms treated with drugs at $25^{\circ} \mathrm{C}$ for $48 \mathrm{~h}$, and $(\mathrm{H})$ quantitative analysis of inflammatory cytokines by using ImageJ and GraphPad Prism 7. All results are presented as mean $\pm \operatorname{SEM}(n=2) ; * p<0.0001$ ([aspirin] $=[\mathrm{BIBA}]=20 \mu \mathrm{M})$.

\section{Inhibition of PICs}

The immune system could be overactivated indirectly and lead to the release of various neurotoxic mediators and PICs, which may contribute to neuronal damage or degeneration in the brain of AD patients. The pro-inflammatory M1 phenotype of microglia is predominant at the site of neuroinflammation and related to the release of PICs, which may cause tissue damage and cell death. During chronic activation of microglia, sustained exposure of neurons to PICs, such as IL-6, IL-1 $\beta$, and TNF- $\alpha$, can cause neuronal dysfunction and cell death. ${ }^{62}$ To verify the anti-inflammatory activity of BIBA, the expression of PICs and neurotoxic mediators in BV-2 microglia was investigated by the Western blot after incubation with LPS or A $\beta 42$ and BIBA, with LPS- or A $\beta 42$-treated BV-2 cells as controls. As shown in Fig. 5A and B, the expression of PICs and mediators increased markedly when the cells were stimulated by LPS or A 342 as compared with the control group; however, BIBA significantly inhibited their expression under the same conditions.
Cluster of differentiation 86 (CD86) is closely correlated with microglia overactivation and is regarded as a marker of the M1 phenotype of microglia. ${ }^{63}$ To clarify the phenotype of BV-2 cells in the presence of BIBA, we detected the level of CD86 using immunohistochemistry. As shown in Fig. 5C, the expression of CD86 (red) was obviously increased in the A $\beta$-exposed microglia, and decreased after treatment with BIBA, suggesting that BIBA can protect BV-2 cells from overactivation induced by A $\beta 42$. This deactivation ability towards microglia is more obvious than that of adiponectin, an adipokine derived from adipose tissue. ${ }^{64}$

\section{Reduction of $A \beta$ oligomers and overactivation of microglia in vivo}

APP/PS1 double-TG model mice produce elevated levels of human A $\beta$ by expressing mutant human APP and PS1, forming amyloid plaques as early as 4 months old and losing cognition when 6-8 months old. ${ }^{65}$ To verify the inhibitory effect of BIBA on the formation of $\mathrm{A} \beta$ oligomers and plaques in vivo, the brains of 

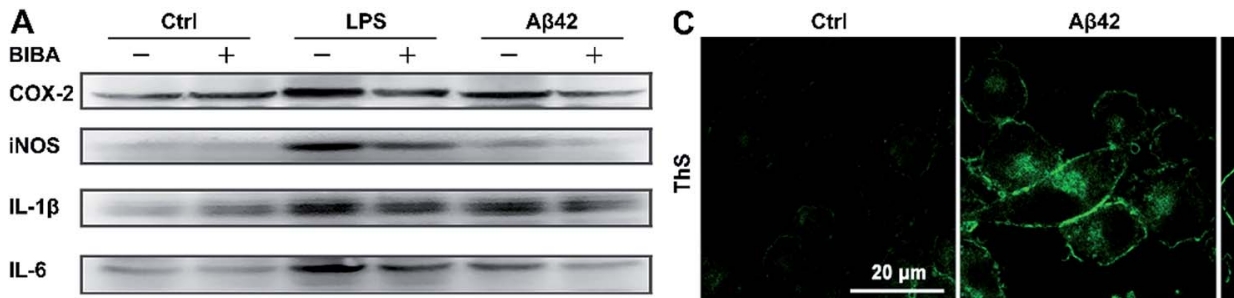
$A \beta 42+B \mid B A$
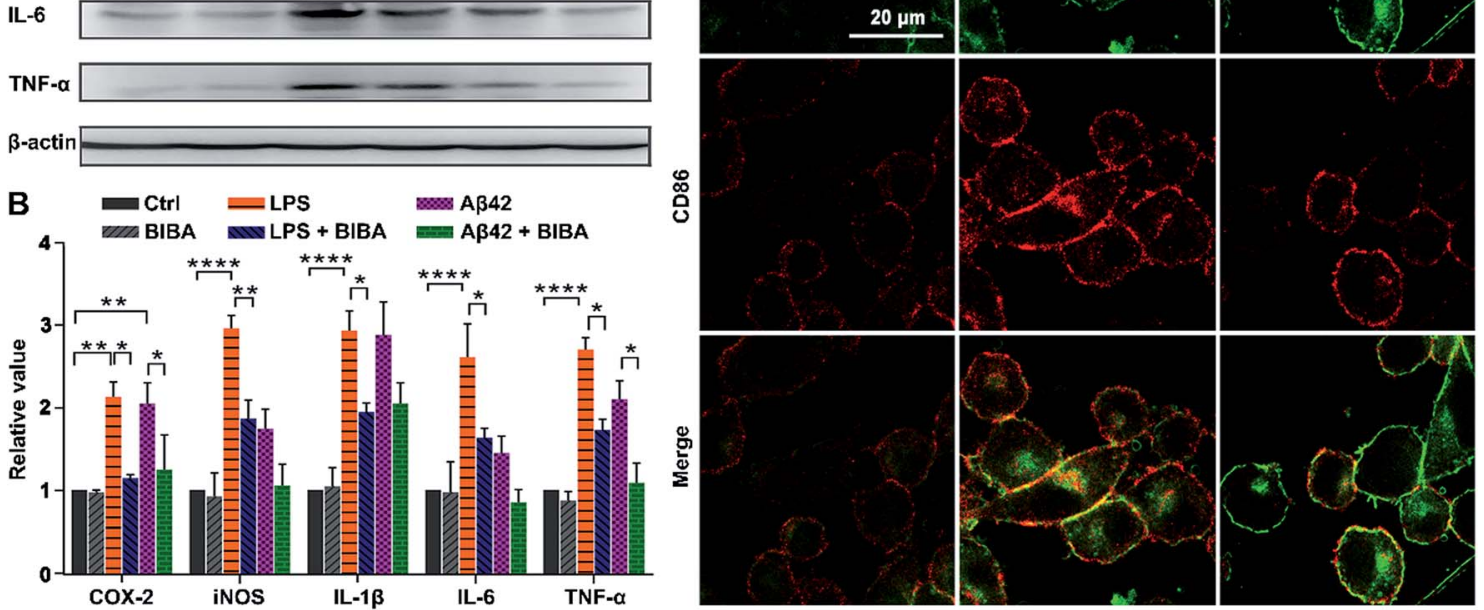

Fig. 5 Inhibition effect of BIBA on PICs. (A) Western blot and (B) quantitative analysis of PICs and mediators in BV-2 cells stimulated by LPS or $A \beta 42$ in the presence or absence of $B I B A$ at $37^{\circ} \mathrm{C}$ for $12 \mathrm{~h}$, and $(C)$ immunofluorescence images showing the expression of $C D 86$ in $A \beta$-exposed BV2 microglia in the presence or absence of BIBA. The results are presented as mean \pm SEM $(n=2) ; * * * * P<0.0001, * * * P<0.001, * * P<0.01$ and $* P<0.1\left([\mathrm{LPS}]=1 \mu \mathrm{g} \mathrm{mL} \mathrm{m}^{-1},[\mathrm{~A} \beta 42]=10 \mu \mathrm{M}\right.$, and $\left.[\mathrm{BIBA}]=20 \mu \mathrm{M}\right)$.

the BIBA-treated APP/PS1 mice were examined by immunohistochemical analysis and the Western blot. As shown in Fig. 6, green fluorescence spots of $\mathrm{A} \beta$ plaques are observed in the brain of untreated and aspirin-treated 9-month old mice after staining with ThS, which could visualize the dense-core $\mathrm{A} \beta$ plaques, ${ }^{\mathbf{6}}$ while the formation of plaques was dramatically inhibited in

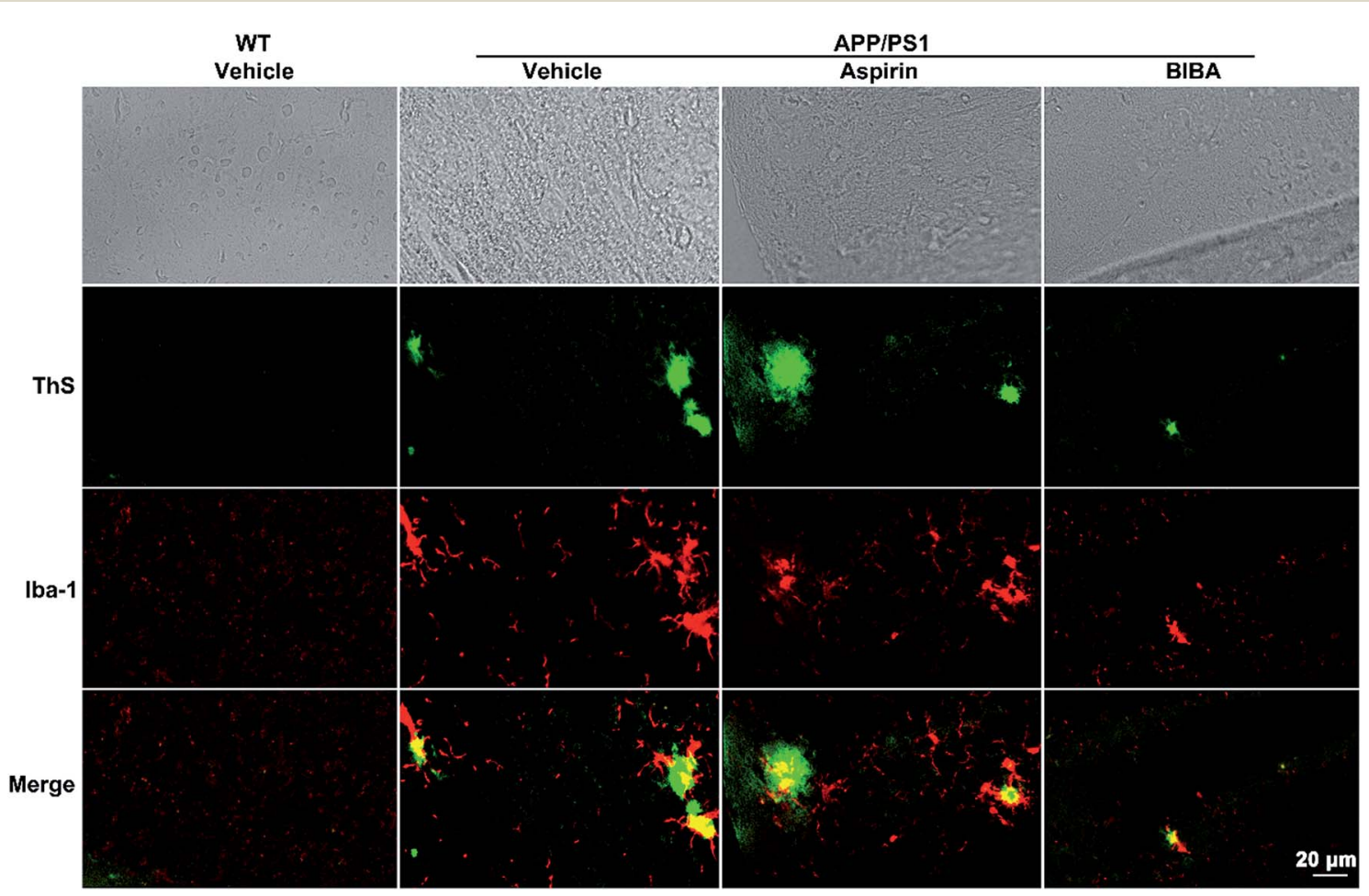

Fig. 6 Reduction of A $\beta$ expression and microglia overactivation. Histochemical analyses of A $\beta$ deposition (green) and Iba-1 (red) in WT and APP/ PS1 mice brain after treatment with vehicle, aspirin $\left(1.4 \mathrm{mg} \mathrm{kg}^{-1}\right)$ and BIBA $\left(2 \mathrm{mg} \mathrm{kg}^{-1}\right)$, respectively, every 3 days for 3 months. 
the BIBA-treated APP/PS1 mice. The formation of A $\beta$ oligomers was also examined by the Western blot. BIBA greatly decreased the amount of oligomeric species in soluble fractions; however, the effect of aspirin seems to be weaker than the reported observations possibly due to the lower dosage (Fig. S8 $\dagger$ ). ${ }^{34} \mathrm{~A} \beta$ monomers did not appear because in APP/PS1 mice A $\beta$ exists mainly in the form of neurotoxic oligomers. These results are consistent with those observed for C. elegans, thus confirming that BIBA can effectively reduce the $\mathrm{A} \beta$ plaques and oligomers formed in the brain of AD mice.

Abnormal accumulation of $\mathrm{A} \beta$ induces overactivation of microglia in the brain, which is closely associated with neuron injury in $\mathrm{AD}^{67}$ Calcium-binding protein Iba-1 is specifically expressed in brain microglia and up-regulated in activated microglia. ${ }^{68}$ Therefore, we detected the Iba-1-positive cells and the expression of Iba-1 in the brain of APP/PS1 mice by immunofluorescence staining. As shown in Fig. 6 and S9, $\dagger$ strong activation of microglia (red spots) was found around the $\mathrm{A} \beta$ plaques (green spots) in the brain of APP/PS1 mice; by contrast, BIBA markedly reduced the expression of Iba-1. Aspirin did not show significant effects on the activation of microglia. These results show that the aberrant elevation of microglia activation in the APP/PS1 mice was alleviated and the surrounding A $\beta$ species was reduced after the administration of BIBA.

In view of the above properties, we assessed the protective effect of BIBA on the spatial judgement and hippocampal memory of APP/PS1 mice (6-month-old, male) by Morris water maze (MWM) tests after drug administration for 3 months. ${ }^{69}$ On the 4 th day during the acquisition phase, the BIBA-treated APP/ PS1 mice seem to perform better than the aspirin-treated and the control group, as reflected by a reduction in escape latency time (Fig. S10B $\dagger$ ), with more annulus crossing and longer time spending in the target quadrant in the probe trial (Fig. S10C and $\mathrm{D} \dagger$ ). No obvious toxicity was observed on BIBA at a dose of $10 \mathrm{mg}$ $\mathrm{kg}^{-1}$ based on the mortality, changes in body weight and hair loss (Fig. S11†). These preliminary results suggest that BIBA could ameliorate the $A \beta$-related learning and memory deficits in the APP/PS1 mice.

\section{Mode of interaction between BIBA and A $\beta$}

Given that BIBA can inhibit the self- or metal-induced $A \beta$ aggregation and prevent A $\beta$-induced cell death, we
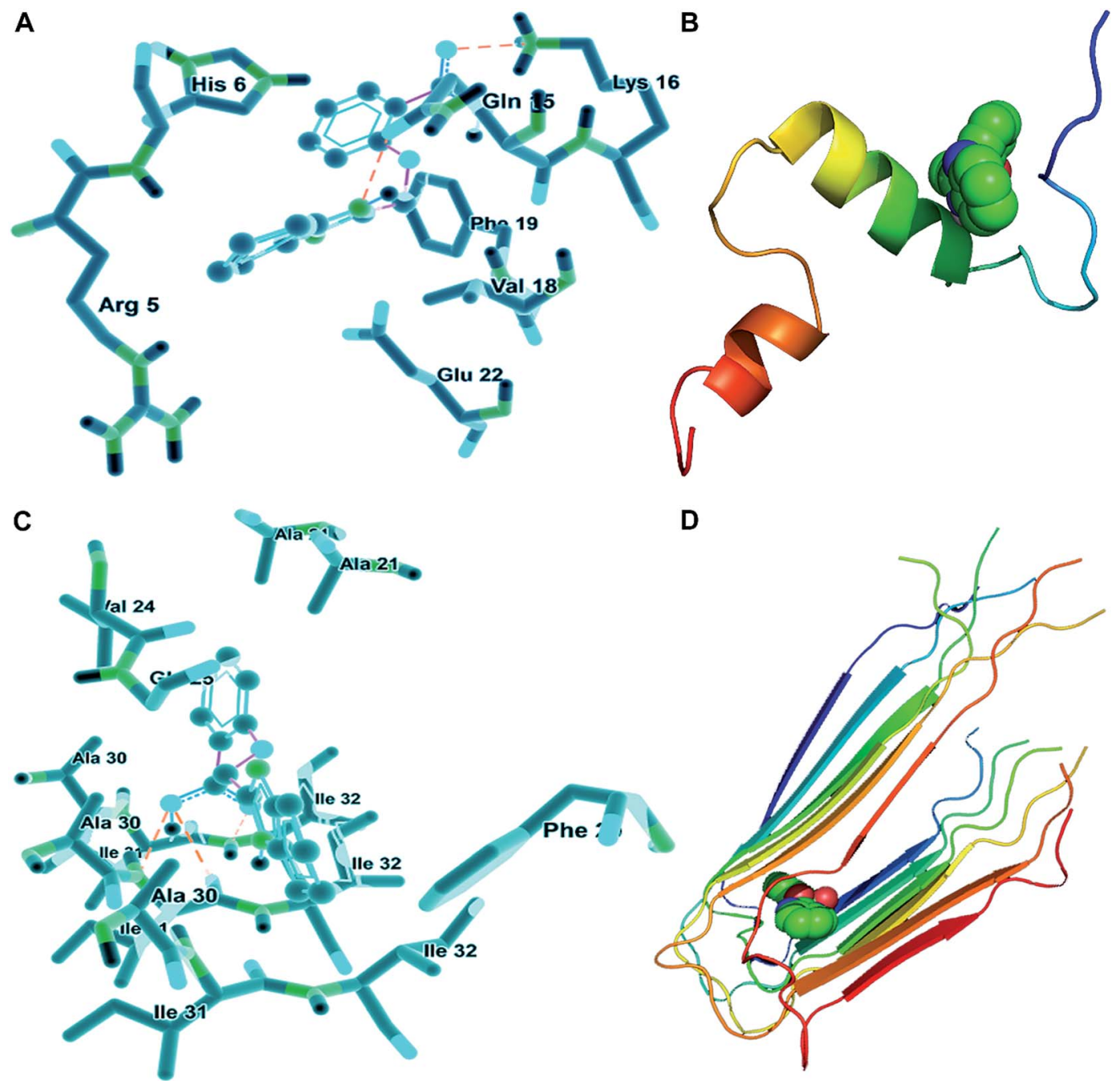

Fig. 7 Calculated surroundings of BIBA-A 340 monomers ( $A$ and $B$ ) and fibrils (C and D). 


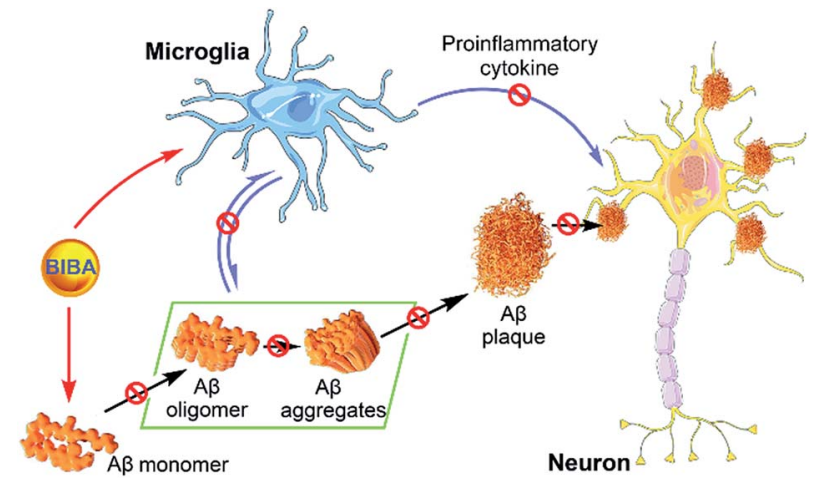

Fig. 8 Schematic diagram showing the mechanism of BIBA-mediated protection of neurons in the AD brain.

hypothesized that BIBA may interact with $A \beta$ monomers or oligomers noncovalently and interfere with the formation of fibrils. In order to further understand the possible molecular mechanism for the inhibiton of $\mathrm{A} \beta$ aggregation by BIBA, we adopted the crystallographic data of $A \beta 40$ and optimized the geometry of BIBA to perform the blind docking calculations using Autodock software. ${ }^{42,70}$ As shown in Fig. $7 \mathrm{~A}$, there are seven amino acid residues in A $\beta 40$, which are Glu-22, Phe-19, Val-18, Lys-16, Gln-15, His-6, and Arg-5, taking part in the interaction with BIBA. Among them, Val-18 and Phe-19 are hydrophobic, and the rest are hydrophilic. Two hydrogen bonds involving Gln-15 (2.6871 ̊) and Lys-16 (2.4672 ̊̊) are associated with BIBA, implying that hydrogen bonding as well as hydrophobic and van der Waals forces contributed to the interaction. In A $\beta 40$ fibrils, BIBA is located in the central hydrophobic residues and remains in contact with Ile- 31 and -32 through hydrogen bondings (Fig. 7C). The interaction energies between BIBA and related amino acids of $\mathrm{A} \beta 40$ monomers or fibrils are listed in Table S4. $\dagger$ These results illustrate that BIBA may interfere in the $\mathrm{A} \beta$ self-aggregation through weak interactions with the amino acid residues in A $\beta 40$. Fig. 7B and D depict the lowest energy conformation of BIBA with monomeric and fibrillar $\mathrm{A} \beta 40$, respectively. The weak interaction between BIBA and $\mathrm{A} \beta 40$ was further studied by ${ }^{1} \mathrm{H}$ NMR. The proton signals assignable to the imidazole of His residues only slightly shifted in the presence of BIBA (Fig. S12 $\dagger$ ), which suggests that BIBA may affect the chemical environment of protons in $A \beta 40$ through H-bonding interactions. ${ }^{71}$

\section{Conclusions}

Alzheimer's disease is characterized by several hallmarks, including $\mathrm{A} \beta$ plaques, NFTs, overactivation of microglia, neuronal loss and cognitive impairment. ${ }^{72}$ Currently, many single-targeted drug candidates are designed to solubilize $A \beta$ aggregates or dissociate NFTs, and some of them have entered different stages of pre-clinical or clinical development. However, most of them failed finally in clinical trials, suggesting that single-target drugs only achieve limited effects on the $\mathrm{AD}$ progression.${ }^{73,74} \mathrm{AD}$ is usually diagnosed at late stages when substantial $A \beta$ aggregates and PICs are produced, and irreversible neuron death and cognitive impairments have occurred. Hence, drugs with $A \beta$ aggregates or inflammation as the single target cannot break the vicious cycle between $A \beta$ aggregation and neuroinflammation. By contrast, dual-target BIBA significantly decreased the level of $A \beta$ fibrils and inhibited the self- or metal-induced $A \beta$ aggregation; meanwhile, it suppressed the intracellular expression of pro-inflammatory mediators and cytokines, thereby protecting microglia from overactivation induced by $A \beta 42$. In addition, BIBA could reduce the expression of apoptosis-related proteins and prevent the apoptosis of neural cells induced by $\mathrm{A} \beta$ aggregates. The synergistic effect between the inhibition of $A \beta$ aggregation and suppression of neuroinflammation exerted by BIBA is depicted in Fig. 8.

In conclusion, a difunctional neuromodulator (BIBA) was designed in this study. BIBA can (1) inhibit self- and metalinduced $A \beta$ aggregations, (2) diminish neuroinflammation in microglia, (3) prolong the lifespan and attenuate $A \beta$-induced paralysis in $\mathrm{A} \beta$-transgenic $C$. elegans, and (4) reduce $\mathrm{A} \beta$ plaques, oligomers and neuroinflammation in the brain of $\mathrm{AD}$ model mice. Mechanism studies suggest that BIBA holds back the metal-induced $A \beta$ aggregation by chelating with metal ions, interferes with the $A \beta$ self-aggregation by interacting with amino acid residues, and inhibits the neuroinflammation by suppressing PICs in microglia. Therefore, BIBA is a multi-target anti-AD agent that may alleviate the progress of $\mathrm{AD}$ through a synergistic mechanism. The design of BIBA represents a new conception for the treatment of $\mathrm{AD}$ and opens a promising avenue for the development of anti-AD agents.

\section{Conflicts of interest}

There are no conflicts to declare.

\section{Acknowledgements}

We are grateful to the National Natural Science Foundation of China (Grants 21877059, 31570809, and 31700714) for financial support.

\section{Notes and references}

1 W. Q. Henry and M. L. Frank, N. Engl. J. Med., 2010, 362, 329344.

2 L. M. Ittner and J. Götz, Nat. Rev. Neurosci., 2011, 12, 67-72. 3 A. Lleó, S. M. Greenberg and J. H. Growdon, Annu. Rev. Med., 2006, 57, 513-533.

4 J. Hardy and D. J. Selkoe, Science, 2002, 297, 353-356.

5 I. Kuperstein, K. Broersen, I. Benilova, J. Rozenski, W. Jonckheere, M. Debulpaep, A. Vandersteen, I. SegersNolten, K. V. D. Werf, V. Subramaniam, D. Braeken, G. Callewaert, C. Bartic, R. D'Hooge, I. C. Martins, F. Rousseau, J. Schymkowitz and B. D. Strooper, EMBO J., 2010, 29, 3408-3420.

6 J. P. Cleary, D. M. Walsh, J. J. Hofmeister, G. M. Shankar, M. A. Kuskowski, D. J. Selkoe and K. H. Ashe, Nat. Neurosci., 2005, 8, 79-84. 
7 K. Blennow, Nat. Med., 2010, 16, 1218-1222.

8 M. G. Savelieff, A. S. DeToma, J. S. Derrick and M. H. Lim, Acc. Chem. Res., 2014, 47, 2475-2482.

9 X. H. Wang, X. Y. Wang and Z. J. Guo, Coord. Chem. Rev., 2018, 362, 72-84.

10 S. Bolognin, D. Drago, L. Messori and P. Zatta, Med. Res. Rev., 2009, 29, 547-570.

11 X. H. Wang, X. Y. Wang, C. L. Zhang, Y. Jiao and Z. J. Guo, Chem. Sci., 2012, 3, 1304-1312.

12 J. McLaurin, M. E. Kierstead, M. E. Brown, C. A. Hawkes, M. H. L. Lambermon, A. L. Phinney, A. A. Darabie, J. E. Cousins, J. E. French, M. F. Lan, F. Chen, S. S. N. Wong, H. T. J. Mount, P. E. Fraser, D. Westaway and P. S. George-Hyslop, Nat. Med., 2006, 12, 801-808.

13 F. S. Yang, G. P. Lim, A. N. Begum, O. J. Ubeda, M. R. Simmons, S. S. Ambegaokar, P. Chen, R. Kayed, C. G. Glabe, S. A. Frautsch and G. M. Cole, J. Biol. Chem., 2005, 280, 5892-5901.

14 S. Kumar, A. Henning-Knechtel, I. Chehade, M. Magzoub and A. D. Hamilton, J. Am. Chem. Soc., 2017, 139, 1709817108.

15 K. Rezai-Zadeh, D. Shytle, N. Sun, T. Mori, H. Hou, D. Jeanniton, J. Ehrhart, K. Townsend, J. Zeng, D. Morgan, J. Hardy, T. Town and J. Tan, J. Neurosci., 2005, 25, 88078814.

16 D. J. Selkoe, Science, 2012, 337, 1488-1492.

17 F. Panza, G. Logroscino, B. P. Imbimbo and V. Solfrizzi, Curr. Opin. Psychiatr., 2014, 27, 128-137.

18 M. Staderini, M. A. Martín and M. L. Bolognesi, Chem. Soc. Rev., 2015, 44, 1807-1819.

19 L. I. Labzin, M. T. Heneka and E. Latz, Annu. Rev. Med., 2018, 69, 437-449.

20 C. Nicolás, L. Fernandez-Sanchez, L. Campello, V. Maneu, P. D. 1. Villa, P. Lax and I. Pinilla, Prog. Retinal Eye Res., 2014, 43, 17-75.

21 J. Koenigsknecht-Talboo and G. E. Landreth, J. Neurosci., 2005, 25, 8240-8249.

22 N. Zilka, Z. Kazmerova, S. Jadhav, P. Neradil, A. Madari, D. Obetkova, O. Bugos and M. Novak, J. Neuroinflammation, 2012, 9, 47-56.

23 G. Azizi, N. Khannazer and A. Mirshafiey, Am. J. Alzheimer's Dis. Other Dement., 2014, 29, 415-425.

24 V. Calsolaro and P. Edison, Alzheimer's Dementia, 2016, 12, 719-732.

25 C. R. Stewart, L. M. Stuart, K. Wilkinson, J. M. Gils, J. S. Deng, A. Halle, K. J. Rayner, L. Boyer, R. Zhong, W. A. Frazier, A. Lacy-Hulbert, J. E. Khoury, D. T. Golenbock and K. J. Moore, Nat. Immunol., 2010, 11, 155-161.

26 F. J. Sheedy, A. Grebe, K. J. Rayner, P. Kalantari, B. Ramkhelawon, S. B. Carpenter, C. E. Becker, H. N. Ediriweera, A. E. Mullick, D. T. Golenbock, L. M. Stuart, E. Latz, K. A. Fitzgerald and K. J. Moore, Nat. Immunol., 2013, 14, 812-820.

27 B. Kaminska, Biochim. Biophys. Acta, 2005, 1754, 253-262.

28 L. Zuroff, D. Daley, K. L. Black and M. Koronyo-Hamaoui, Cell. Mol. Life Sci., 2017, 74, 2167-2201.

29 Y. Tang and W. D. Le, Mol. Neurobiol., 2016, 53, 1181-1194.
30 S. Piirainen, A. Youssef, C. Song, A. V. Kalueff, G. E. Landreth, T. Malm and L. Tian, Neurosci. Biobehav. Rev., 2017, 77, 148-164.

31 J. C. Breitner and P. P. Zandi, N. Engl. J. Med., 2001, 345, 1567-1568.

32 P. S. Aisen, Lancet Neurol., 2002, 1, 279-284.

33 ADAPT Research Group, Neurology, 2007, 68, 1800-1808.

34 S. Côté, P.-H. Carmichaela, R. Verreault, J. Lindsaya, J. Lefebvred and D. Laurin, Alzheimer's Dementia, 2012, 8, 219-226.

35 A. A. Reinke and J. E. Gestwicki, Chem. Biol. Drug Des., 2011, 77, 399-411.

36 J. R. Vane and R. M. Botting, Thromb. Res., 2003, 110, 255258.

37 S. Chandra, M. Jana and K. Pahan, J. Neurosci., 2018, 38, 6682-6699.

38 S. Ayyadevara, M. Balasubramaniam, S. Kakraba, R. Alla, J. L. Mehta and R. J. S. Reis, Antioxid. Redox Signaling, 2017, 27, 1383-1396.

39 H. van de Waterbeemd and E. Gifford, Nat. Rev. Drug Discovery, 2003, 2, 192-204.

40 H. Kozlowski, M. Luczkowski, M. Remelli and D. Valensinc, Coord. Chem. Rev., 2012, 256, 2129-2141.

41 L. J. Zhu, Y. Song, P.-N. Cheng and J. S. Moore, J. Am. Chem. Soc., 2015, 137, 8062-8068.

42 X. Ma, J. A. Hua, K. Wang, H. M. Zhang, C. L. Zhang, Y. F. He, Z. J. Guo and X. Y. Wang, Inorg. Chem., 2018, 57, 1353313543.

43 Y.-S. Cheng, Z.-t. Chen, T.-Y. Liao, C. Lin, H. C.-H. Shen, Y.-H. Wang, C.-W. Chang, R.-S. Liu, R. P.-Y. Chen and P.-H. Tu, EMBO Mol. Med., 2017, 9, 703-715.

44 S. Kumar and A. D. Hamilton, J. Am. Chem. Soc., 2017, 139, 5744-5755.

45 G. Wen, W. J. Qin, D. Y. Chen, Y. Q. Wang, X. Yue, Z. Y. Liu, Y. N. Cao, J. Du, B. H. Zhou and X. Z. Bu, Chem. Commun., 2017, 53, 3886-3889.

46 J. W. Um, H. B. Nygaard, J. K. Heiss, M. A. Kostylev, M. Stagi, A. Vortmeyer, T. Wisniewski, E. C. Gunther and S. M. Strittmatter, Nat. Neurosci., 2012, 15, 1227-1285.

47 A. K. Sharma, S. T. Pavlova, J. Kim, D. Finkelstein, N. J. Hawco, N. P. Rath, J. Kim and L. M. Mirica, J. Am. Chem. Soc., 2012, 134, 6625-6636.

48 D. J. Tew, S. P. Bottomley, D. P. Smith, G. D. Ciccotosto, J. Babon, M. G. Hinds, C. L. Masters, R. Cappai and K. J. Barnham, Biophys. J., 2008, 94, 2752-2766.

49 K. Bettayeb, J. C. Chang, W. J. Luo, S. Aryal, D. Varotsis, L. Randolph, W. J. Netzer, P. Greengard and M. Flajolet, Proc. Natl. Acad. Sci. U. S. A., 2016, 113, 5412-5417.

50 S. Lee, X. Zheng, J. Krishnamoorthy, M. G. Savelieff, H. M. Park, J. R. Brender, J. H. Kim, J. S. Derrick, A. Kochi, H. J. Lee, C. Kim, A. Ramamoorthy, M. T. Bowers and M. H. Lim, J. Am. Chem. Soc., 2014, 136, 299-310.

51 S. M. Monte, Y. K. Sohn and J. R. Wands, J. Neurol. Sci., 1997, 152, 73-83.

52 C. B. Lu, W. M. Fu, G. S. Salvesen and M. P. Mattson, NeuroMol. Med., 2002, 1, 69-79. 
53 Z. Z. Zhu, T. Yang, L. Zhang, L. L. Liu, E. M. Yin, C. L. Zhang, Z. J. Guo, C. Xu and X. Y. Wang, Eur. J. Med. Chem., 2019, 168, 330-339.

54 Y. J. Guan, Z. Du, N. Gao, Y. Cao, X. H. Wang, P. Scott, H. L. Song, J. S. Ren and X. G. Qu, Sci. Adv., 2018, 4, eaao6718.

55 S. Alavez, M. C. Vantipalli, D. J. S. Zucker, I. M. Klang and G. J. Lithgow, Nature, 2011, 472, 226-229.

56 G. McColl, B. R. Roberts, T. L. Pukala, V. B. Kenche, C. M. Roberts, C. D. Link, T. M. Ryan, C. L. Masters, K. J. Barnham, A. I. Bush and R. A. Cherny, Mol. Neurodegener., 2012, 7, 57-66.

57 T. Kaletta and M. O. Hengartner, Nat. Rev. Drug Discovery, 2006, 5, 387-398.

58 C. D. Link, Proc. Natl. Acad. Sci. U. S. A., 1995, 92, 9368-9372.

59 G. McColl, B. R. Roberts, A. P. Gunn, K. A. Perez, D. J. Tew, C. L. Masters, K. J. Barnham, R. A. Cherny and A. I. Bush, J. Biol. Chem., 2009, 284, 22697-22702.

60 Y. J. Wu, Z. X. Wu, P. Butko, Y. Christen, M. P. Lambert, W. L. Klein, C. D. Link and Y. Luo, J. Neurosci., 2006, 26, 13102-13113.

61 D. L. Rebolledo, R. Aldunate, R. Kohn, I. Neira, A. N. Minniti and N. C. Inestrosa, J. Neurosci., 2011, 31, 10149-10158.

62 M. T. Heneka, M. P. Kummer and E. Latz, Nat. Rev. Immunol., 2014, 14, 463-477.

63 F. Zhang, R. J. Zhong, S. Li, Z. F. Fu, C. Cheng, H. B. Cai and W. D. Le, Front. Aging Neurosci., 2017, 9, 282.

64 J. Y. Song, S.-M. Choi and B. C. Kim, Front. Cell. Neurosci., 2017, 11, 64.

65 D. F. Cao, H. L. Lu, T. L. Lewis and L. Li, J. Biol. Chem., 2007, 282, 36275-36282.

66 T. Yang, L. Yang, C. L. Zhang, Y. Q. Wang, X. Ma, K. Wang, J. Luo, C. Yao, X. Y. Wang and X. H. Wang, Inorg. Chem. Front., 2016, 3, 1572-1581.
67 M. T. Heneka, M. J. Carson, J. E. Khoury, G. E. Landreth, F. Brosseron, D. L. Feinstein, A. H. Jacobs, T. Wyss-Coray, J. Vitorica, R. M. Ransohoff, K. Herrup, S. A. Frautschy, B. Finsen, G. C. Brown, A. Verkhratsky, K. Yamanaka, J. Koistinaho, E. Latz, A. Halle, G. C. Petzold, T. Town, D. Morgan, M. L. Shinohara, V. H. Perry, C. Holmes, N. G. Bazan, D. J. Brooks, S. Hunot, B. Joseph, N. Deigendesch, O. Garaschuk, E. Boddeke, C. A. Dinarello, J. C. Breitner, G. M. Cole, D. T. Golenbock and M. P. Kummer, Lancet Neurol., 2015, 14, 388-405.

68 D. G. Walker and L.-F. Lue, Alzheimer's Res. Ther., 2015, 7, 56. 69 S.-H. Yang, D. K. Lee, J. Shin, S. Lee, S. Baek, J. Kim, H. Jung, J.-M. Hah and Y.-S. Kim, EMBO Mol. Med., 2017, 9, 61-77.

70 G. M. Morris, R. Huey, W. Lindstrom, M. F. Sanner, R. K. Belew, D. S. Goodsell and A. J. Olson, J. Comput. Chem., 2009, 30, 2785-2791.

71 J. E. Del Bene and M. J. T. Jordan, J. Am. Chem. Soc., 2000, 122, 4794-4797.

72 E. E. Spangenberg, R. J. Lee, A. R. Najafi, R. A. Rice, M. R. P. Elmore, M. Blurton-Jones, B. L. West and K. N. Green, Brain, 2016, 139, 1265-1281.

73 S. Salloway, R. Sperling, N. C. Fox, K. Blennow, W. Klunk, M. Raskind, M. Sabbagh, L. S. Honig, A. P. Porsteinsson, S. Ferris, M. Reichert, N. Ketter, B. Nejadnik, V. Guenzler, M. Miloslavsky, D. Wang, Y. Lu, J. Lull, I. C. Tudor, E. Liu, M. Grundman, E. Yuen, R. Black and H. R. Brashear, N. Engl. J. Med., 2014, 370, 322-333.

74 R. S. Doody, R. G. Thomas, M. Farlow, T. Iwatsubo, B. Vellas, S. Joffe, K. Kieburtz, R. Raman, X. Y. Sun, P. S. Aisen, E. Siemers, H. Liu-Seifert and R. Mohs, N. Engl. J. Med., 2014, 370, 311-321. 